\title{
Action and Self-Location in Perception
}

\author{
Susanna Schellenberg
}

\begin{abstract}
I offer an explanation of how subjects are able to perceive the intrinsic spatial properties of objects, given that subjects always perceive from a particular location. The argument proceeds in two steps. First, I argue that a conception of space is necessary to perceive the intrinsic spatial properties of objects. This conception of space is spelled out by showing that perceiving intrinsic properties requires perceiving objects as the kind of things that are perceivable from other locations. Second, I show that having such a conception of space presupposes that a subject represent her location in relation to perceived objects. More precisely the thesis is that a subject represents her location as the location from which she both perceives objects and would act in relation to objects were she to act. So I argue that perception depends on the capacity to know what it would be to act in relation to objects.
\end{abstract}

It is striking that only agents are perceivers. I argue that it is no coincidence. Perceivers are not just passive receivers of information. They are agents in the world. The thesis that perception is dependent on action has a long history in philosophy, but has rarely been argued for in any detail. Aristotle can be read as arguing in De Anima that only beings that are self-movers can perceive. More recently, Gibson (1979), Baldwin (1998, 2003), Hurley (1998), Kelly (2001; 2004), Thompson and Valera (2001), and Noë (2004, forthcoming) have argued in different ways that perception and action are interrelated. ${ }^{1}$ I will defend a version of the thesis that perception depends on action. I reject the thesis that perception depends on token actions and will argue that perception depends rather on the capacity to act.

In section one, I discuss Noë's sensorimotor knowledge thesis. The basic idea of the thesis is that perceiving the spatial properties of objects involves practical knowledge of how the appearances of objects change as our spatial relation to perceived objects changes. This thesis is subject to a host of objections. In the rest of the paper, I present a different understanding of the relation between action and perception. My argu-

\footnotetext{
${ }^{1}$ Arguably our perceptions guide our actions by presenting objects in ways appropriate for high-level action selection. Clark (2001) and Matthen (2005) defend different versions of such an instrumental relation between perception and action. I am not denying that action and perception are related in an instrumental manner, but the thesis that I am arguing for is stronger than that perception is instrumentally related to action. The thesis is that perception is constitutively dependent on action.
}

Mind, Vol. 116 . 463 . July 2007

ㄷ) Schellenberg 2007 
ment involves two steps. First I show that a practical understanding of space is necessary to perceive the intrinsic spatial properties of objects. Call this the spatial know-how thesis. In a second step, I show that this thesis presupposes that subjects represent their location in relation to perceived objects. More specifically, I argue that subjects represent their location as the location from which they both perceive objects and would act in relation to objects were they to act. Call this the self-location thesis. I argue for the spatial know-how thesis in section two and for the self-location thesis in section three.

The motivation for discussing the action-dependency of perception is to answer the question of how one can perceive the intrinsic spatial properties of objects, even though one always perceives objects from a particular point of view. Despite the fact that one perceive objects from a location, one can perceive their perspective-independent shapes; one perceives two same-sized objects located at different distances from oneself as the same size; and-more contentiously-one perceives objects as having surfaces facing away from oneself, even though one is visually confronted only with the surfaces facing towards oneself. ${ }^{2}$ More generally one perceives the intrinsic spatial properties of objects, even though there is an epistemic primacy to the ways object are presented. By intrinsic properties I mean the perceivable properties that an object has that are independent of a perceiver's location. For the present discussion the most salient intrinsic properties are the shapes and sizes of objects. The way an object is presented in a perceiver's egocentric frame of reference is determined by the intrinsic properties of the object and the location of the perceiver. If the way an object is presented is recognized as being external and mind-independent, it can be analysed in terms of properties the object has, namely situation-dependent properties. Situation-dependent properties are properties of the object given the perceiver's location. They are a function of the object's intrinsic properties and the perceiver's location. ${ }^{3}$

The fact that perceiving the intrinsic properties of an object is epistemically dependent upon perceiving its situation-dependent properties is a direct consequence of the spatio-temporal nature of perception. If one necessarily perceives objects from a particular location at a particular time, then the rear-sides of objects, say, are not immediately

\footnotetext{
${ }^{2}$ There are breakdown conditions. When one perceives an object from sufficiently close up, one is no longer able to tell whether it is, say, a sphere or a cube. Similarly, when one is far away from an object, one is no longer able to perceive its specific spatial properties.

${ }^{3} \mathrm{I}$ argue for these ideas and the more general thesis that perception is a three-place relation between subjects, objects, and situations, rather than a two-place relation between subjects and objects in my manuscript.
} 
perceptually available, whereas the surfaces in the line of sight of the perceiver are immediately perceptually available. One can imagine subjects whose sensory organs are extended such that they can perceive an object from several angles simultaneously. The location from which a subject perceives can be extended in all sorts of ways. The location's extension and the angle of the visual field depend on the particular kind of perceiver. But it is a necessary feature of perception that subjects perceive from somewhere at some time. As a consequence there is a necessary distinction between how an object is presented given one's location and how the object is independently of one's location. In other words, there is a necessary distinction between the situation-dependent properties and the intrinsic properties of an object.

If it is right that one always perceives objects from a particular location, but none the less can perceive their intrinsic properties, then an explanation is needed for how this can be so. There are at least two ways of understanding this demand for explanation. One is as a demand for a scientific explanation of how sensory systems filter out invariant features of the environment, such as the size and shape of objects, from the variant features that are due to the subject's location in relation to the perceived object. Such a scientific explanation concerns a process on a subpersonal level the outcome of which may or may not be available to perceptual consciousness. Another way is to understand the demand for explanation epistemologically: if the ways objects are presented given the perceiver's location are epistemically primary, then an explanation is needed for how the perceiver can have knowledge of the intrinsic properties of objects through perception. Such an epistemological explanation concerns conscious mental states on a personal level. ${ }^{4}$ These explanatory tasks are no doubt interconnected. But I think it will prove useful to explore the epistemological aspect of the problem.

The aim of this paper is to contribute to the epistemological explanation. In order to do so, it is necessary to specify what makes it possible to perceive the shape and size of objects despite the fact that perceiving the intrinsic properties of an object is epistemically dependent upon perceiving its situation-dependent properties. Call the abstraction-condition the condition that must be satisfied to perceive intrinsic properties of

\footnotetext{
${ }^{4}$ Justifying this contrast between scientific and epistemological explanations would require a paper of its own. For a discussion of the problems of demarcating philosophical and scientific explanations in philosophy and cognitive science, see Shapiro 2004. Hartfield (1990) shows how the very same questions about the nature of spatial perception change their focus when discussed from a scientific or a philosophical perspective. For a defence of the distinction between personal and subpersonal levels of explanation, see Burge 1986, McDowell 1994, and Hornsby 20oo. For a criticism, see Bermúdez 2000 and Davies 2000.
} 
objects. The label 'abstraction-condition' is fitting, as there is a sense in which one perceives intrinsic spatial properties in abstraction from the vantage point one happens to have. With this label in hand the aim of this paper can be formulated more precisely as identifying the abstraction-condition by considering the action-dependency of perception.

One objection that could immediately be raised is that there is no reason to appeal to action to explain how it is that we perceive intrinsic spatial properties. It might be argued that the reason why we perceive the shape and size of objects is that we have a concept of objects as solid and temporally located three-dimensional space-occupiers. Such an approach, however, would over-intellectualize perception. It is far from obvious that a concept of objects is necessary to perceive objects. It is important to acknowledge that perception is a primitive cognitive skill and to bring out the minimal requirements for perception. More importantly, the very idea of a spatial object is arguably grounded in perception. This is just to say that one has the concept of objects as solid, three-dimensional space-occupiers only because one's perception is structured in a certain way. If the aim is to bring out what this structure is, then presupposing that perception is so structured would beg the question.

The argument of this paper is limited to visual perception of spatial properties. So when I speak of perceivers, I mean beings that are capable of visually perceiving the intrinsic spatial properties of objects. When I speak of action, I do not have in mind a notion that has anything to do with reason-giving practices-so I do not have in mind the notion that is often used today in philosophical debates on action. I have an older notion in mind; one that Kant makes use of when he speaks of actio as one side of the contrast pair actio and reactio. I will discuss the notion of action at issue in more detail in section three. Among other things, it will have to be discussed whether self-movement is necessary for perception.

\section{The sensorimotor knowledge argument}

A recent influential approach to meeting the abstraction-condition is to argue that perception involves practical knowledge of the effects that changes in our spatial relation to objects have on the appearances of these objects. Call this the sensorimotor knowledge account. There are two elements to such an account. One is that experience of the intrinsic spatial properties of objects requires practical knowledge of the different 
ways objects look given different viewpoints on the objects. Call this the variation thesis. The sensorimotor knowledge argument conjoins the variation thesis with the thesis that perception is dependent on action. The basic idea of the action-dependency thesis as it figures in the sensorimotor knowledge argument is that one's perception of, say, a round plate is constituted by sensorimotor knowledge of the form: if one were to move to the right, the sensory stimulation caused by the plate would change thus and so, namely in the characteristic way that the sensory stimulation caused by circular objects varies as one's spatial relation to the perceived object changes. Grasping such practical conditionals connecting action and perception is what allows one to perceive the intrinsic shape of the object. The idea is not that perception involves explicit knowledge that such and such laws of sensorimotor contingencies hold, but rather that perception involves practical knowledge that is expressed in one's expectations and readiness to act on one's perceptions. It might be possible to have such knowledge explicitly, but what is involved in perception need not be explicit knowledge. It is important to note that the variation thesis is independent of the more controversial actiondependency thesis. ${ }^{5}$

Noë (2004) presents a version of this view. He argues that we perceive a plate as circular because we have knowledge of the way its appearance changes as the spatial relation between oneself and the object changes. The 'because' that forms the relation between perceiving the plate as circular and having it presented to us can be understood in purely causal terms or it can be understood constitutively. ${ }^{6}$ Noë understands the ways objects look as two-dimensional geometrical projections of the objects in view: 'We experience that the plate is round and that it looks elliptical from here. Its elliptical look from here is a genuine property of the plate' (2004, p. 172). No doubt, geometrical projections play a role in the processing of perception, ${ }^{7}$ but Noë insists that circular objects look elliptical to us over and above looking circular. As he puts it: 'A satisfying account of perception must explain how the silver dollar can look both circular and elliptical' (forthcoming, p. 1). Noë understands the ways objects are presented in terms of so-called P-shapes and

\footnotetext{
${ }^{5}$ For a discussion, see Matthen 2006.

${ }^{6}$ Noë's formulations vary from 'perceiving is constituted by the exercise of a range of sensorimotor skills' (2004, p. 90, emphasis added) over 'how things look is constrained by my sensorimotor knowledge' (p. 9o, emphasis added) to 'perceptual experience acquires content as a result of sensorimotor knowledge' (p. 9, emphasis added). For a discussion of causal and constitutive readings of the sensorimotor knowledge argument, see Block 2005. For a critical discussion of the distinction between causal and constitutive relations, see Hurley (forthcoming).

${ }^{7}$ For a defence of this idea, see Marr 1982.
} 
P-sizes. A P-shape is 'the shape of the patch needed to occlude the object on a plane perpendicular to the line of sight' (2004, p. 83). Similarly, a P-size is 'the size of a patch we can imagine drawn on the occlusion plane' (2004, p. 83). The idea that a circular object at an angle looks elliptical implies that the ways objects are presented are understood as projections on a two-dimensional plane located perpendicular to one's line of sight.

There is no reason to think of the distinction between the ways objects are presented given one's location and the way they are independently of one's location in terms of a distinction between twodimensional and three-dimensional spatial properties. Objects are presented in three-dimensional space and, arguably, we are aware of the ways objects are presented in three-dimensional space. Denying that one perceives two-dimensional geometrical projections of objects in the normal case is not to deny that one can take a realistic painter's point of view. When one looks at an object as a realistic painter does, one is aware of the planar geometrical projection of the circular object. Looking at an object in such a way requires that one have an understanding of a planar geometrical projection as well as awareness of one's location in relation to the perceived object. There is, however, no reason to think that one must be aware of one's vantage point in such a sophisticated way in a regular case of perception.

One way to circumvent this problem is to understand sensorimotor couplings as playing a role only at a subpersonal level. Hurley (1998) argues along these lines. She understands the interdependence between the contents of intentions and of perceptions on a personal level as emerging from the co-dependency of perception and action on dynamically circular subpersonal relations. In particular, she argues that feedback from motor outputs to sensory inputs plays a critical role within the subpersonal dynamic system. So in contrast to Noë, she explains perception of intrinsic spatial properties in terms of the way sensorimotor information processed on a subpersonal level feeds into our perceptual awareness. In a similar vein, Thompson and Varela (2001) argue that what an organism senses is determined by cycles of sensorimotor coupling with the environment, which are in turn mediated in the brain by multiple neocortical regions and subcortical structures.

Such a subpersonal version of the sensorimotor knowledge argument can avoid the problem of how to specify what it is that subjects are aware of as changing as their spatial relations to perceived objects changes. But by doing so it cannot explain the fact that subjects can be aware of changes regarding the situation-dependent properties of 
objects. This should not be read as a criticism of Hurley or Thompson and Varela's theories, since it is not their concern to account for awareness of changes in the ways objects are presented. But an approach on which representations of situation-dependent properties play a role only on a subpersonal level will not do, if we acknowledge that subjects can be aware of the situation-dependent properties over and above the intrinsic properties of objects. ${ }^{8}$

This first objection does not go to the heart of the sensorimotor knowledge argument, since the argument does not require that appearances be thought of as two-dimensional geometrical projections. We can reject the idea that the ways objects are presented are two-dimensional planar projections, but none the less hold on to the idea that perception is sensitive to the difference between the ways objects look from our point of view and how they fill out space. We can distinguish between intrinsic and situation-dependent properties of objects, both of which are structured in three-dimensional space and both of which are available to perceptual consciousness. By doing so, we can acknowledge that perception is egocentrically organized, while accounting for the fact that we perceive the intrinsic spatial properties of objects.

The sensorimotor knowledge argument is however subject to two more fundamental objections. The second objection concerns the variation thesis. To perceive a single enduring and distinct object one must be able to recognize two distinct appearances as appearances of the same object. Furthermore, one must be able to distinguish the case in which two appearances are appearances of the same object from cases in which two appearances are of different objects. ${ }^{9}$ In so far as the variation thesis requires at least two encounters with an object (either past or present), it raises the question of how one can tell whether or not the encounters are encounters with the same object. Sensorimotor knowledge allows one to recognize any particular appearance of an object as only one of many possible ways that an object can present itself. But this thought is not the same as the thought that different appearances are recognized as of a single enduring object. Furthermore, if perception of objects requires having different encounters with objects, then the problem arises of how the appearances that arise from these different encounters are unified into a perception of an object. Even if we presuppose that the appearances are appearances of the same object, this would still leave open the question of how the appearances are inte-

\footnotetext{
${ }^{8}$ Of course, these brief remarks do not do justice to their sophisticated accounts of the interdependency of perception and action.

${ }^{9}$ This line of thought is due to Strawson (1966), Evans (1980), and Cassam (1997).
} 
grated into the perception of an object. I will return to this objection at the end of section two. I will refer to it as the unification objection.

The third objection concerns the action-dependency thesis, more specifically, the role of movement in sensorimotor knowledge. If the requirement is simply that our perceptions be integrated in sensorimotor patterns allowing us to anticipate how our perceptions would change were our spatial relations to the perceived objects to change, then it is not obvious why it would not be sufficient that either our body be moved in relation to perceived objects or objects be moved in relation to our bodies. There is no reason why perception should require self-movement. Call this the sentient statue objection.

The response to this objection depends on the details of the notion of sensorimotor knowledge at issue. A modest version of the sensorimotor knowledge argument stops short at the thesis that perception involves practical knowledge of the effects of movement on perception. According to a radical version, sensorimotor knowledge can only be acquired through token actions. Noë defends the radical version, arguing that 'only through self-movement can one test and so learn the relevant patterns of sensorimotor dependence' (2004, p. 13).

On the modest version of the sensorimotor knowledge argument, it is not obvious why it would not be sufficient to be a sentient statue. As a consequence, the thesis that perception is dependent on action loses its appeal. On the radical version, however, the ability to self-activate movement is necessary for perception. The possibility of a perceiving subject that never self-moves is ruled out, since the sensorimotor knowledge that is said to be necessary for perception can only be gained through token actions. So, on the face of it, the sentient statue objection does not hold against the radical version of the sensorimotor knowledge argument.

But the radical version presupposes the problematic idea that perceiving an object's shape requires that one know the sensorimotor profile of the shape-type that the object exemplifies. So perceiving a round object requires that one know the sensorimotor profile of round objects. If one has not been acquainted with an object exemplifying the same spatial properties, then one cannot, on Noë's account, have the relevant sensorimotor knowledge to perceive the object. Since sensorimotor knowledge can only be acquired by testing the relevant patterns of sensorimotor dependence, one can only have acquired that sensorimotor knowledge through self-movement in relation to objects that exemplify the same shape-type as the perceived object. 
No doubt one typically learns the token shapes of particular objects through perception. But contra Noë, it cannot be right that one can only perceive the intrinsic shape of a particular object once one has learnt the patterns of sensorimotor dependence for the relevant shapetype. The idea that one learns to perceive shape-types is odd in light of our capacity to perceive the spatial properties of objects without previously having seen an object exemplifying the same spatial properties. ${ }^{10}$ If this observation is correct, then it cannot be right that perceiving an object requires that one has learnt the specific sensorimotor profile of the shape-type that the object exemplifies. One could defend the sensorimotor knowledge thesis by arguing that when confronted with an object that exemplifies an unknown shape-type, token actions are necessary to perceive the object's shape. But as I argue in section three, it cannot be right that token actions are necessary in the actual situation of perception.

These problems can be circumvented if perception is not understood as depending on specific knowledge of the ways objects look from different perspectives in the first place. In the rest of the paper, I provide an alternative account of what is required to perceive intrinsic spatial properties. I argue that the requirement for perceiving intrinsic spatial properties is not knowledge of how objects look from different perspectives. The requirement is that one have a practical understanding of space. I will return to the sentient statue objection at the end of section three. I will argue there that perception is not dependent on (past or present) token actions, but rather on the capacity to act.

\section{The spatial know-how argument}

I have considered one way of meeting the abstraction-condition. I will now argue for an alternative approach to meeting the abstraction-condition. The main thesis is that a practical understanding of space is necessary to perceive the intrinsic spatial properties of objects. I spell out the spatiality of perception by arguing that perceiving intrinsic spatial properties requires perceiving objects as perceivable from locations other than the one that one happens to occupy.

When perceiving an object one is immediately visually confronted only with its situation-dependent properties, that is, with the way the

\footnotetext{
${ }^{10}$ Noë acknowledges that 'as we get to more complicated forms, such as animal bodies, plants, and so forth, the mathematics needed to determine the sensorimotor profile of an object gets more complicated'. But he holds on to the thesis that sensorimotor knowledge is necessary for specific shape-types by asserting that 'our visual perceptual skills, however, are that sophisticated, encompassing these complex (but ultimately manageable) relationships' (2004, p. 78).
} 
object is presented in one's egocentric frame of reference. None the less there is a sense in which one's perception is not just limited to the surfaces of the object that are in one's line of sight. How can this fact be accounted for? One might say that a subject must have an understanding of objective space that allows her to step outside her egocentric frame of reference and map objects into an objective, viewpoint-independent frame of reference. The idea is that objects are mapped independently of a point of view.

To understand the possibility that perception is organized in an objective frame of reference, it is helpful to consider the difference between imagination, perception, and visualization. One might be able to imagine a shape without having a point of view on it. We do so when we represent, say, a circle as the set of all points equidistant from one point. It is not clear, however, what it could be to visualize an object without having a (pretend) vantage point. One can visualize an elephant. At any moment of visualization one will have a pretend vantage point on the scene. Although there are no physical constraints on switching viewpoints when visualizing an object, at any given moment there are physical constraints on what one can visualize from one's pretend vantage point. ${ }^{11}$ So even when a subject visualizes an object she has a pretend point of view.

This difference between imagination, on the one hand, and visualization and perception, on the other, is a direct consequence of the spatial nature of perception. As argued above, perception is the kind of mental activity that necessarily occurs from a location. The spatial nature of perception pertains to cases of visualization, since cases of visualization mirror perceptual states. When a subject visualizes an object, she necessarily visualizes the object from a pretend point of view. In so far as perception and mental states that mirror perceptual states necessarily occur from a (pretend) point of view, one cannot step outside one's egocentric frame of reference when perceiving an object, nor can one step outside one's pretend egocentric frame of reference when visualizing an object. If this is right, then the abstraction-condition cannot be met by mapping objects in a way that leaves out (potential) viewpoints altogether. This is just to say that the distinction between perception of situation-dependent properties and perception of intrinsic properties cannot be understood on the model of a distinction between egocentric and objective frames of reference.

\footnotetext{
${ }^{11}$ I treat perceiving and visualizing as analogous to one another. For discussions of the Berkeleian distinction between perceiving and visualizing, see Williams 1966 and Peacocke 1985. 
Now if it is not possible to step outside of one's egocentric frame of reference, then how can one transcend the egocentricity of perception to perceive intrinsic spatial properties? I will consider three further possible ways of meeting the abstraction-condition and will argue for the third. The first option is to have a conception of the way an object looks from viewpoints other than one's own. The second option is to have a conception that the object is perceived from points of view other than one's own. The third option is to have a conception that the object is perceivable from points of view other than one's own.

On the first option, perceiving inherent spatial properties requires having knowledge of what objects look like from points of view other than one's own. This is just the variation thesis on which the sensorimotor knowledge argument relies. On this account, knowledge of what objects look like from other locations constitutes perceptual content. In so far as such knowledge figures in perceptual content, perception of objects is not limited to the information projected onto one's retina. As I argued in the last section, the view requires at least two encounters with an object (either past or present). One of the problems with this account is that it is only once one has unified two appearances of the object into the perception of an object that the relation to the object counts as a perception.

On the second suggestion, perceiving inherent spatial properties requires practical knowledge that objects are perceived from points of view other than one's own. Kelly $(2001 ; 2004)$ defends a version of this view. The view is originally formulated by Merleau-Ponty:

To see is to enter a universe of beings which display themselves ... Thus every object is the mirror of all others. When I look at the lamp on my table, I attribute to it not only the qualities visible from where I am, but also those which the chimney, the walls, the table can 'see'; the back of my lamp is nothing other than the face which it 'shows' to the chimney. I can therefore see an object in so far as ... each of them treats the others around it like spectators of its hidden aspects and a guarantee of their permanence. (1962, p. 68)

Such an approach avoids the problem of having knowledge of what objects look like from other locations and unifying this knowledge into the perception of an object. It leads, however, to the bigger problem of how the different possible actual viewpoints can be unified into the perception of the object. So while the idea that perception involves knowledge of what an object looks like from viewpoints other than one's own (Noë's variation thesis) leads to the problem of how these different appearances of the object are unified into the perception of the object, the idea that perception involves knowledge that the object 
is perceived from other points of view (Kelly's thesis) leads to the problem of how the different actual points of view are unified into the perception of the object.

\subsection{Allocentric frames of reference and alter-ego vantage points}

I have considered three ways of meeting the abstraction-condition: the idea that we map objects in an objective, viewpoint-independent frame of reference, Noë's idea that perception involves practical knowledge of the ways objects look from points of view other than one's own, and Kelly's idea that perception involves practical knowledge that objects are perceived from points of view other than one's own. In this section, I will develop a way of meeting the abstraction-condition that avoids the problems of the options considered so far. The basic idea is that perceiving intrinsic spatial properties requires that objects are perceived as perceivable from points of view other than one's own. In contrast to the variation thesis, this idea does not require that a subject have knowledge of what objects look like from other locations. It requires only that a subject must have a practical conception of space that involves understanding that there are different possible perspectives on any three-dimensional space-occupier. This is what I call the spatial know-how thesis.

This thesis can be spelled out more precisely by introducing the notion of an alter-ego vantage point. ${ }^{12}$ An alter-ego vantage point is a location that the perceiver understands as a possible vantage point. This notion is closely connected to the familiar notion of an allocentric frame of reference. An allocentric frame of reference is a frame of reference that is centred on a point in space distinct from the one that the perceiver is occupying. An alter-ego vantage point is a particular way of understanding the location on which an allocentric frame of reference is centred. It is a location that the perceiver understands as a possible point of view. Campbell's distinction between absolute and egocentric space is helpful here (1994, pp. 5 f.). While absolute space is the conception of space that a disengaged theorist has, egocentric space is the conception of space that a participant has, that is, a subject who has something to do in that space. An alter-ego vantage point is a vantage point that one has as a participant, more precisely, as a potential participant since it is not the location that one is occupying in the moment of perception. Another way of articulating the same point is that an alterego vantage point is an allocentric frame of reference that is engaged. It is the focal point of a potential egocentric frame of reference. In light of

${ }^{12}$ I owe this label to Grush. See his 2001. 
the notion of an alter-ego vantage point, the spatial know-how thesis can be formulated more precisely. Perceiving intrinsic spatial properties requires entertaining alter-ego points of view on the object. ${ }^{13}$

Now why is moving from egocentric to allocentric frames of reference not sufficient to perceive the intrinsic spatial properties of objects? ${ }^{14}$ Why do we need alter-ego points of view? The reason is that the information provided in an allocentric frame of reference is only available to us through a potential egocentric frame of reference. In order to show why, it is necessary to consider in more detail the nature of the egocentric organization of perception. Determining the egocentric frame of reference for movement is straightforward. It is determined by the direction of the movement and the bodily parts relevant for the movement. The coordinates of the movements involved in walking are very different from the coordinates of the movements involved in writing. In the one case, they are centred on the main axis of the body; in the other case, they are centred on the hand. This might lead one to think that the frame of reference of visual perception is centred on the eyes. But this cannot be right. As the following example shows, the position of one's body in relation to a perceived object is at least as important as the position of one's eyes. When one turns one's head to the left one does not perceive the objects to the left of one's body as in front of oneself. If this is right, then the coordinates of perception cannot be centred simply on one's eyes.

What else is involved? One conceivable answer is to say that the axes of the egocentric frame of reference are determined by minimal spatial concepts, such as up, down, left, right, in front, and behind, with the centre identified as here. One might object that this suggestion implies

\footnotetext{
${ }^{13}$ The question of how allocentric and egocentric frames of reference are combined in alter-ego points of view is an open empirical question. For an overview of competing explanations, see Paillard 1991 as well as Klatzky 1998. For a discussion of the neural mapping from egocentric to allocentric spatial frames of reference, see Goodale and Anderson 1998. For a discussion of the same issue with regard to cognitive processing, see Iachini and Ruggiero 2006. Finally, for a discussion of the mapping of allocentric and egocentric frames of reference in a computational model of spatial development, see Hiraki and Phillips 1998. Grush (2001, see in particular Sect. 2.3) and Thompson (2007, see in particular Ch. 9) provide helpful philosophical interpretations of this literature.

${ }^{14}$ It is conceivable that a creature that is able to navigate in space has neither alter-ego vantage points nor egocentric frames of reference. Indeed, there are creatures that navigate in space by relating to a fixed point in their environment, for instance the South or North Pole. So they navigate in space by relating only to an allocentric frame of reference. O'Keefe (1998) describes this model of spatial navigation as the slope-centroid model. Although a creature can navigate in space in such an allocentric frame of reference, the information provided in the allocentric frame of reference is arguably not available for perceptual consciousness. I am arguing that the information cannot be available for the creature's perceptual consciousness because it is not connected to its egocentric frame of reference.
} 
that only creatures that have the concept of, say, left can perceive objects as being to their left. ${ }^{15}$ There are good reasons not to limit perception to creatures that have conceptual skills. One can, however, avert this objection, while holding on to the basic idea of the suggestion. What is crucial for determining the coordinates of perception are the spatial locations from which possible movements originate and the directions of the relevant movements. The axes of our egocentric frame of reference are determined by our dispositions to act that bring about a practical understanding of basic spatial directions. ${ }^{16}$ This practical understanding of basic spatial directions is a kind of spatial know-how. ${ }^{17}$ The idea of spatial know-how is related to Evans's thought that an understanding of spatial directions is not simply related to the place we occupy, but is related rather to the possibilities for action that one has given the way one occupies that location. When I tilt my head, I do not see objects on the verge of sliding off the surface of the earth. The reference of 'up' is not determined by the direction of my head, but rather by how I would move my body given the position of my body. ${ }^{18}$

Now one could object that having such spatial know-how just is having basic spatial concepts. It is unproblematic to think of the spatial know-how in terms of spatial concepts as long as one is willing to ascribe these concepts to any creature that is capable of object-directed movement and capable of perceiving the intrinsic spatial properties of objects. It is unproblematic, since the spatial concepts are not what enable spatially oriented movement and actions. The direction of explanation goes the other way. Dispositions to act bring about the spatial orientation that allows subjects to locate objects in their visual field. This means that one has spatial concepts only in so far as these concepts are grounded in one's dispositions to act. In other words, one's perception is structured egocentrically not because one has spatial concepts, but because one has dispositions to act. These dispositions to act allow

\footnotetext{
${ }^{15}$ This objection is due to Jesse Prinz.

${ }^{16}$ For a discussion of dispositions to act, see Mumford 1998 and 1999. For a helpful discussion of different ways of representing space, see Grush 2004 and forthcoming.

${ }^{17}$ Following Ryle (1949), I am using 'know-how' to refer to a practical, non-intellectual conception that non-rational beings could have. Ryle's conception of know-how has been famously criticized by Carr (1979) and more recently by Stanley and Williamson (2001). In short, the criticism is that 'know-how' expresses the same relation as 'know-that'. Addressing this criticism would only affect the wording of my argument. My argument does not depend on the terminology. For a critical discussion of Stanley and Williamson's argument and a defence of a concept of know-how, see Hornsby 2004. Her concern is with semantic know-how, but a parallel argument can be given for spatial know-how.

${ }^{18}$ Evans attributes this thought to Taylor (1964).
} 
one to have the spatial know-how that can be expressed with spatial concepts.

I have considered three different ways of determining the axes of the egocentric structure of perception: through the location of sensory organs, through spatial concepts, and through dispositions to act. I argued that the coordinates of perception are determined by our dispositions to act on perceived objects. In light of these considerations, we can see more clearly why allocentric frames of reference are not sufficient to meet the abstraction-condition. One can gain the spatial information that is structured in an allocentric frame of reference only because one understands that were one to occupy the location on which the allocentric frame of reference is centred, one's dispositions to act on the perceived object would change. If this is right, then the location on which the allocentric frame of reference is centred must be an alter-ego vantage point, that is, a location that one understands as a potential viewpoint.

A different way of articulating the same idea is that one must be able to create what could be called an intentional web that is recentred as one changes one's position in space. The intentional web is determined by the directions and distances one would move were one to come in contact with the objects around oneself. Peacocke expresses a similar thought when he says that perception involves perspectival sensitivity (1983, p. 67). On his view, dispositions to perform bodily movements change as one's spatial relations to perceived objects change. This is just to say that one's behaviour displays perspectival sensitivity in so far as it is spatially dependent on the particular perceptions one has. A creature that has the capacity to have what I call alter-ego points of view need not actually relocate. Nor does it need to know how precisely its dispositions to act would change would it occupy a different location. It must only be able to entertain the possibility of relocating and remapping its spatial orientation. So it must only be able to entertain the possibility of adapting its dispositions to perform bodily movements to potential changes of its location.

I have argued that perceiving the intrinsic spatial properties of objects requires that an object be perceived as perceivable from points of view other than the one that one happens to occupy. In order to perceive objects as perceivable from other points of view one must be able to move from egocentric to allocentric frames of reference. These allocentric frames of reference must be engaged in so far as one understands them as possible vantage points on the perceived object. The alter-ego points of view are thus tied to egocentric frames of reference 
in so far as they involve remapping the dispositions to act in relation to a perceived object.

The spatial know-how thesis differs in two respects from the variation thesis on which the sensorimotor knowledge argument is based. The variation thesis states that perception of intrinsic spatial properties is dependent on knowledge of the different ways objects look given different viewpoints on the object. In contrast, the spatial know-how thesis does not require appeal to the specific ways objects look from points of view other than the one that one occupies. The requirement for perceiving intrinsic spatial properties is more flexible: perception requires only a practical understanding of space. Such a practical understanding of space involves knowledge of the possibility of other vantage points on the perceived object.

A second difference is that perception of objects is not made possible by conjoining different ways objects look to a unified whole. We perceive intrinsic spatial properties by perceiving objects as perceivable from different possible locations. According to Noë's variation thesis, subjects perceive intrinsic spatial properties in virtue of having knowledge of what objects look like from other locations. A subject needs at least two appearances of an object to have the sensorimotor knowledge necessary to perceive the intrinsic spatial properties of an object. There are two ways of gaining such sensorimotor knowledge. Either one has two encounters with the object from different perspectives in the very situation of perception or one has knowledge of what the object looks like from other perspectives based on past encounters with objects that exemplify the same shape-type. As Noë puts it for the case of perceiving a cube: 'As you move with respect to the cube, you learn how its aspect changes as you move-that is, you encounter its visual potential. To encounter its visual potential is thus to encounter its actual shape. When you experience an object as cubicle merely on the basis of its aspect, you do so because you bring to bear, in this experience, your sensorimotor knowledge of the relation between changes in cube aspects and movement. To experience the figure as a cube, on the basis of how it looks, is to understand how its look changes as you move' (2004, p. 77). In both cases, it is only once one has unified the two appearances into the perception of an object that the relation to the object can be a perception of a cube.

According to the spatial know-how thesis, perception of intrinsic spatial properties does not depend on subjects having two encounters with an object (either past or present). Just one encounter is required. For this reason alone the spatial know-how thesis does not face the uni- 
fication problem that arises for the variation thesis. While the variation thesis requires that we have two encounters with objects, the spatial know-how thesis requires only that the object is perceived as the kind of thing that is perceivable from other locations. Perceiving the intrinsic spatial properties of an object is integrated in the perspective-dependent aspect of perception.

\section{The self-location argument}

In the last section, I argued that perceiving intrinsic spatial properties requires perceiving objects as perceivable from locations other than the one that one happens to occupy. In this section, I will show that this idea presupposes that one represent one's location in relation to objects. The basic idea is that one represents one's location as the point of origin of one's perceptions and actions. More precisely, the idea is that one represents one's location as the location from which one both perceives objects and would act in relation to objects were one to act.

If we take seriously the idea that how things look from one's location is a relational property, then one's vantage point must play a role in perceptual content in so far as it forms the point of origin of an egocentric frame of reference. ${ }^{19}$ Perceptual content is organized egocentrically, representing perceived objects as located in relation to oneself. But how can one's location - which is simply a fact about the world-play a role at the level of content? And why would perception alone or action alone not be sufficient to represent one's location?

The answer to these questions leads back to the thesis that spatial know-how is determined by one's dispositions to act given the way one occupies one's location. One needs at least an understanding of what it would mean, say, to reach out to a glass in order to perceive it as within reach. Likewise, one needs an understanding of what it would mean to move one's body upwards in order to understand the spatial direction of up. ${ }^{20}$ The frame of reference of action and perception changes as the spatial relations between oneself and the perceived objects change, and these changes allow one to represent one's location in relation to these objects. Through changes in perception brought about by changes in the spatial relations to objects one can triangulate back to one's location. If this is right, then perception alone or action alone cannot be sufficient to gain the self-location necessary for perception. These con-

\footnotetext{
${ }^{19}$ Peacocke (1999) can be read as defending this idea.

${ }^{20}$ Baldwin (2003, p. 197) develops a similar idea when he argues that perceiving something as near is to perceive it as within easy reach.
} 
siderations bring out not only how self-location comes about, but also what is represented. One represents one's location as the vantage point of perception and the location from which changes in perception are registered that are brought about through changes in the spatial relations to perceived objects. ${ }^{21}$

The representation of one's location is immediate and non-relational. The suggestion is not that a subject consciously computes her position in space by reflecting on her spatial relation to objects. When a cat perceives a chair it might not see it as a chair, but it sees something that is located in a certain relation to itself and something onto which it can jump. Through perception it gauges the distance it must jump to land on the chair. Its location in relation to the chair must figure in its perception for it to be able to flex its muscles so as to land on the chair. I do not mean to assume anything about cat-perception. What is at issue does not depend on whether cats can perceive intrinsic spatial properties. The point is only to show that the representation of the perceiver's location is understood practically in a way that is not only unproblematic to ascribe to cats, but moreover necessary to ascribe to cats to explain what cats do.

What I mean by 'non-relational' can best be explained in terms of the standard distinction between direct and indirect representations. One represents one's location indirectly in so far as one only represents it by perceiving an object. By contrast, the representation of perceived objects is direct. Perceptual attention is focused on objects, not on one's location or one's mental state of perception. One does not take a third person attitude towards oneself, nor does one represent one's location by way of self-reflection or introspection. This is just to say that the thesis that one perceives objects in relation to one's location does not imply that one perceives objects to one's right or to one's left. It implies only that one perceives objects to the right or to the left. So the idea that one perceives objects in relation to one's location does not depend on being aware of oneself as standing in spatial relations to those objects. Nor does it require that one be aware of one's location. This is not to

\footnotetext{
${ }^{21}$ Brewer argues in a different vein that perception is dependent on action in virtue of perception's role in the control and coordination of spatial behaviour: 'the basic idea is that various perceptions are organized and integrated into a representation of the subject's spatial environment in virtue of their role in controlling his behaviour with respect to that environment in accordance with his purposes' (1992, p. 27). The idea I am suggesting brings in action at a more fundamental level. For reasons analogous to the ones articulated against the sensorimotor knowledge argument, I do not take it to be necessary that subjects control or coordinate their spatial behaviour through perception. The thesis that subjects control and coordinate their spatial behaviour through perception implies that token actions are necessary for perception. I argue towards the end of this section that it cannot be right that token actions are necessary for perception.
} 
deny that there might be an intelligible notion of experiencing oneself perceiving. The point is simply that whether or not one experiences oneself as the point of origin of one's perceptions has no bearing on the present discussion. Campbell's distinction between monadic and relational spatial representations is helpful here (1994, p. 119). It shows how it can be that one represents objects as standing in egocentrically specified spatial relations without either awareness of one's location or awareness of oneself as standing in spatial relations to those objects. We can endorse the thesis that perception involves a relation between the perceiver and the perceived objects while omitting one side of the relation. ${ }^{22}$ If this is right, then representing one's location requires only what Campbell calls monadic spatial representations.

One might want to say that even though awareness of what it feels like to perceive is not what brings about the representation of one's location, it constitutes a form of self-awareness. While the awareness involved in attending to an object is transitive, the self-awareness that could arguably be said to be in play in perception is intransitive. It is intransitive since one is only aware of doing the perceiving in so far as one is perceiving an object. ${ }^{23}$ The argument presented here does not, however, require that representing one's location is as cognitively rich as self-awareness. The thesis is that spatial perception depends on representing one's location, but not in a way that requires or amounts to self-awareness. The idea is rather that one represents one's location in a dual mode: the point of origin of perception presents itself as the point of origin for bodily movement. One occupies one position from which one both perceives and would act were one to act.

Now against the sensorimotor knowledge argument the objection was raised that it is not obvious that self-movement is required. The objection was, recall, that sensorimotor knowledge is not constituted by actual self-movements, but rather sensorimotor knowledge of how one's perceptions would change were the spatial relation between

\footnotetext{
${ }^{22}$ Cassam expresses a similar idea when he writes that 'the fact that a creature lacks the conceptual resources to articulate its perceptions in first-person terms does not mean that they do not in fact represent things as standing in various spatial relations to it' $(1997$, p. 78). For an excellent discussion of relational properties that can appear as monadic properties, see Gupta 1999.

${ }^{23}$ This understanding of self-location is related to the role that Strawson gives to the self in perception: 'Since these synthesizing activities do not, after all, yield any kind of self-knowledge or self-awareness other than that which ordinary empirical self-consciousness supplies, it seems that we may have to look for the explanation of the possibility of self-ascription of experiences in the nature of the outcome of the synthesizing activities rather than in any special awareness of those activities themselves or of the powers exercised in performing them' (1966, p. 96). It is the act of perceiving an object that brings about the representation of one's location, not awareness of the activities themselves.
} 
oneself and perceived objects to change. If it is only necessary that the spatial relations change, it is not clear why it would not be sufficient to be moved in relation to objects. Moreover, if all that is required is counterfactual knowledge of the effects of movement on perception, then it is not clear why actual movement is required.

An objection could be raised on similar grounds against the selflocation argument. I have argued that the capacity to act is necessary to meet the abstraction-condition. But it is not clear why one must ever actualize this capacity. Furthermore, surely the connections between perception and action are not so tight as to exclude the possibility that someone can perceive intrinsic spatial properties who is not capable of self-movement. If the action-dependency thesis amounts to the thesis that self-movements are necessary in every single event of perception, then it cannot be right. There is however a way of understanding the action-dependency thesis that does not amount to the thesis that perception depends on (past or present) token actions, while being stronger than the thesis that being moved in relation to objects is sufficient to perceive intrinsic spatial properties. To develop such a version of the action-dependency thesis it is necessary to take a closer look at the notion of action.

Action has played a role in both the spatial know-how argument and the self-location argument. Actual self-movement is, however, not necessary for the spatial know-how thesis. What is necessary is only knowledge that one's dispositions to act would change were one to occupy a different location in relation to a perceived object. In this section, I showed that the spatial know-how thesis presupposes the self-location thesis. Perceiving objects as perceivable from other locations requires representing one's location as the origin of action and perception. But the self-location argument concerns capacities to act. So it is not clear that actual self-movement can be shown to be necessary for the capacity to perceive intrinsic spatial properties. Indeed, the self-location argument should not require that actual self-movement is necessary. Certainly a subject who is temporarily unable to act can represent the location from which she perceives and from which she would act were she able to act. It cannot be necessary that one, say, actually reach out to an object that one perceives as within reach.

If this is right, then what we need is a notion of a capacity without requiring that this capacity be acted on. The Aristotelian distinction between first and second actuality of capacities is helpful here (De Anima II.5, $417^{\mathrm{a}} 22-417^{\mathrm{a}} 30$ ). We can distinguish between an English speaker's innate capacity to speak a language, her capacity to speak 
English when she is sleeping (first actuality), and her capacity to speak English when she is talking English (second actuality). The distinction between first and second actuality is the distinction between the developed capacity to do something and the execution of this doing. In light of this distinction, we can say that representing one's location requires first actuality, but not second actuality of one's capacity to act. This implies that were one for whatever reason not able to move at a particular moment (and thus lack second actuality, but not first actuality of one's capacity to act), this would not challenge one's ability to perceive the intrinsic spatial properties of objects. The reason is that one's inability to move at any given moment does not affect one's capacity to know what it would be to act in relation to perceived objects. One would just lack the ability to act on this knowledge. In this sense, representing one's location requires that one have first actuality, but not second actuality of one's capacity to act. First actuality is not itself an activity, but only a capacity to act. Therefore, Aristotle understands it as a kind of potentiality.

The notion of the first actuality of a capacity allows for a way to hold on to the action-dependency thesis without being committed to the implausible requirement that (past or present) token actions are necessary for perception. Although it cannot be necessary that one actually reach out to an object that one perceives as within reach, one must know what it would be to reach out to an object that one perceives as within reach. More generally, one must know what it would be to act in relation to a perceived object. Now, if representing one's location is a capacity that we must ascribe to cats to explain what cats do, then knowing what it would be to act should not be understood in terms of propositional knowledge. Representing one's location cannot be dependent on know-that, but must be dependent on a kind of knowhow. ${ }^{24}$ Take Ginet's (1975) much used example: as you open a door, you need not have thoughts about where the door-handle is, but you are not able to open the door unless you know where the handle is and know how to use it. By identifying knowledge of what it would be to act in relation to a perceived object as know-how, we can recognize that it is knowledge that does not require linguistic abilities.

In so far as such knowledge does not require linguistic abilities it differs from the practical knowledge that Anscombe (1957) is concerned with. The practical knowledge that she is concerned with is knowledge of what one is doing. This is knowledge that one can be wrong about. One can intend to do $x$, but do $y$. Similarly, one can think one is doing

${ }^{24}$ For a discussion of the concept of know-how, see footnote 18 . 
$x$, although one is doing $y$. Knowing what one is doing is a know-that which applies to actions. In contrast to knowledge of what one is doing, the capacity to act is knowledge of what it would be to do something. Knowledge of what it would be to do something is not knowledge that a subject can be right or wrong about. In this respect, it is similar to knowledge of how to do something.

Knowledge of how to do something, however, pertains to determinate actions, such as acquired skills and basic bodily movements. Some capacities to perform a determinate form of action are acquired skills; say the capacity to play the cello. Other capacities to perform a determinate action are arguably not acquired skills; say the capacity to lift one's arm. ${ }^{25}$ The capacity to act is distinct from the capacity to perform a particular kind of action. It is a capacity that is necessary to acquire skills, but it is not itself a capacity to perform a particular kind of action. It is the capacity to act, whatever the activity might be. This is a capacity that one has in virtue of being the kind of creature who is an agent. ${ }^{26}$ Now Ryle introduces the term 'know-how' in a discussion that is concerned with knowledge that is acquired. But although he emphasizes the perfectibility and acquirability of know-how, his account does not rule out know-how that is not acquired. The capacity to act is a kind of know-how, but not one that is acquired. It is knowledge one has in so far as one is an agent. By contrast to an acquired skill, knowing what it would be to act is not something that one gets better at. So although one can acquire skills only in so far as one is the kind of being who has the capacity to act, the capacity to act is not itself an acquired skill. ${ }^{27}$

With this notion in hand, we can cut a path between two unattractive routes: one is that perception is dependent on past or present token

\footnotetext{
${ }^{25}$ One might argue that all actions are by definition acquired skills - even simple actions, such as lifting one's arm. But even on such a view, one can distinguish between the capacity to perform a determinate action and the capacity to act, whatever that action may be. For a discussion of the distinction between acquired skills and capacities that are not acquired, see Broadie 1987.

${ }^{26}$ For a discussion of having capacities in virtue of being a certain kind of creature, see Thompson 2004 .

${ }^{27}$ My argument does not appeal to embodied intentionality, but it is compatible with the thesis that perceivers are necessarily embodied. For discussions of such accounts, see Taylor 1989, Noë 2004, Baldwin 2004, and Kelly 2004. Arguably only embodied beings can have the capacity to act. But even if this is right, it would only be a consequence of my argument that perceivers are embodied. My argument does not itself depend on it. Similarly, the argument for the spatial knowhow thesis implies but does not depend on perceivers being embodied. What is crucial for determining the axes of the egocentric frame of reference is not the perceiver's body, but rather the location from which possible movements in relation to the perceived object originate and the directions of the relevant movements. For purposes of determining the coordinates of perception, subjects need not be conceived of as embodied. They can understood simply as occupying a geometrical location.
} 
actions; the other is that being moved in relation to objects is sufficient to perceive their intrinsic spatial properties. As I argued, it cannot be right that token actions are necessary for perception. But the alternative is not that being moved in relation to objects is sufficient for perception of spatial properties. Nor is the alternative that no movement is required. I am taking a middle route, one that involves the capacity to act. The action that figures in perception is not actual self-activated movement, but rather potential self-activated movement. This capacity to act is a kind of know-how, more precisely it is knowledge of what it would be to act. As the Aristotelian distinction between first and second actuality of capacities allows us to see, this is knowledge that one can have even if one is not able to act on one's capacity.

By taking this middle route, it is possible to circumvent the sentient statue objection while denying that past or present token actions are necessary for perception. In this respect, the action-dependency thesis I have defended differs from both the modest and the radical version of the sensorimotor knowledge thesis. Recall that, according to the modest version, all that is required for perception is knowledge of how appearances of objects would change were the spatial relations between oneself and objects to change. If all that is required is knowledge of the effects of movement on perception, being moved in relation to objects would be sufficient for perception. In contrast to such a view, I argue that the capacity to act is necessary for the perception of intrinsic spatial properties.

According to the radical version, past or present token actions are necessary for perception, since 'only through self-movement can one test and so learn the relevant patterns of sensorimotor dependence' (Noë 2004, p. 13). On this version of the argument, the sensorimotor knowledge that is said to be necessary for perception can only be gained through actual self-movement. As I have argued, it cannot be right that we learn to perceive specific shape-types. We are able to perceive the intrinsic spatial properties of objects without any knowledge of how objects (exemplifying the relevant shape-type) look from other perspectives. In contrast to the radical version, the action-dependency thesis that I have defended does not imply that token actions are necessary for perception. The requirement is only that perceivers have the capacity to act.

This idea is in one respect more modest and in another respect more robust than the sensorimotor knowledge thesis. It is more modest in so far as it implies no commitment to perception being dependent on token actions. It is more robust in so far as the thesis is not simply that 
self-movement is necessary for perception. I have argued that the capacity to act is necessary to perceive the intrinsic spatial properties of objects. Knowledge of what it would be to act distinguishes organisms that have the capacity to act from organisms that prompt or induce movement without having the capacity to act. ${ }^{28}$ Plants change and move, but they do not have knowledge of what it would be to act. This brings us back to the opening thesis that only agents are perceivers. In so far as perception is dependent on the capacity to act, it is not a coincidence that only agents are perceivers.

\section{Conclusion}

Perception is organized egocentrically in so far as objects are perceived from a point of view. As a consequence, perceiving the intrinsic properties of an object is epistemically dependent upon perceiving its situation-dependent properties. But despite the perspectival structure of perception, one can perceive the intrinsic spatial properties of objects. The aim of this paper is to contribute to an epistemological explanation of how this can be. In the first step of my argument, I showed that a practical understanding of space is necessary to perceive intrinsic spatial properties. I spelled out this thesis by arguing that perceiving intrinsic spatial properties requires perceiving objects as perceivable from locations other than the one that one happens to occupy. Perceiving objects as perceivable from other locations in turn requires moving from egocentric to allocentric frames of reference. I argued that these allocentric frames of reference must be engaged in so far as one understands them as different possible vantage points on the perceived object.

In the second step of my argument, I showed that perceiving objects as perceivable from different locations requires representing one's location in relation to objects. The reason is that only by representing one's location can one abstract from the particular vantage point one happens to have and perceive the perspective-independent intrinsic spatial properties. I argued that one represents one's location in relation to objects as the origin of action and perception. More precisely the thesis is that one represents one's location as the location from which one both perceives objects and would act in relation to objects were one to act. I spelled out this thesis by arguing that perception is dependent on

\footnotetext{
${ }^{28}$ The notion of induced movement should be understood in analogy to the notion of selfmovement. The notion of induced movement allows for a description of the movement of, say, sunflowers, while avoiding the implication that plants have a 'self'.
} 
the capacity to act. I identify this capacity as a kind of know-how, namely knowledge of what it would be to act.

So I have shown that although perception is essentially perspectival in so far as one perceives from a location, the possibility for action that is involved in the egocentric organization of perception allows one to represent one's location in relation to perceived objects. The possibility of action allows one to go beyond the egocentric frame of reference and to perceive the intrinsic spatial properties of objects. So paradoxically, it is the egocentricity of perception that allows one to transcend one's egocentric frame of reference. ${ }^{29}$

Philosophy, RSSS

SUSANNA SCHELLENBERG

Australian National University

Canberra, ACT 0200

Australia

susanna.schellenberg@anu.edu.au

\section{References}

Anscombe, G. E. M. 1957: Intention. Oxford: Blackwell.

Aristotle 1984: De Anima, trans. J. A. Smith. Reprinted in Jonathan Barnes 1984. (ed.), pp. 641-92.

Baldwin, Thomas 2004: Introduction to Merleau-Ponty: The World of Perception. London: Routledge, pp. 1-33.

2003: 'Perception and Agency', in Eilan and Roessler 2003, pp. 188200.

—_ 1998: 'Objectivity, Causality, and Agency', in Bermúdez 1998, pp. 107-25.

Barnes, Jonathan (ed.) 1984: The Complete Works of Aristotle. Princeton: Princeton University Press.

Bermúdez, José Luis 200o: 'Personal and Sub-Personal: A Difference without a Distinction'. Philosophical Explorations, 3, pp. 63-82.

(ed.) 1998: The Body and the Self. Cambridge, MA: The MIT Press.

${ }^{29}$ I would like to thank Keith Allen, Bill Brewer, Wylie Breckenridge, Quassim Cassam, Andy Clark, Stephen Engstrom, Anil Gupta, Susan Hurley, Hemdat Lerman, Jesse Prinz, Mohan Matthen, John McDowell, Johannes Roessler, Jonathan Schaffer, Declan Smithies, and Evan Thompson for detailed comments on earlier versions of this paper. I am indebted to Tim Crane, Rick Grush, Sean Kelly, Anders Nes, Christopher Peacocke, Kieran Setiya, and Susanna Siegel for long discussions on the topic of this paper. I am grateful also to audiences at the Universities of Oslo, Oxford, Pittsburgh, and Warwick as well as the Aristotelian Society and Mind Association joint sessions. Thanks, finally, to three anonymous referees and the editor of Mind for their thoughtful comments and suggestions. 
Block, Ned 2005: Review of Alva Noë, Action in Perception'. The Journal of Philosophy, 102, pp. 259-72.

Brewer, Bill 1992: 'Self-Location and Agency'. Mind, 101, pp. 17-34.

Broadie, Sarah 1987: 'Nature and Craft in Aristotelian Teleology', in Pellegrin, pp. 389-403.

Burge, Tyler 1986: 'Individualism and Psychology'. Philosophical Review, 45 , pp. 3-45.

Campbell, John 1994: Past, Space and Self. Cambridge MA: The MIT Press.

Carman, Taylor and Mark Hansen (eds) 2004: Cambridge Companion to Merleau-Ponty. Cambridge: Cambridge University Press.

Carr, David 1979: 'The Logic of Knowing How and Ability'. Mind, 88, pp. 394-409.

Cassam, Quassim 1997: Self and World. Oxford: Clarendon Press.

Clark, Andy 2001: 'Visual Experience and Motor Action: Are the Bonds too Tight?'. Philosophical Review, 110, pp. 445-519.

Davies, Martin 2000: 'Interaction without Reduction: The Relationship between Personal and Sub-Personal Levels of Description'. Mind and Society, 2, pp. 87-105.

Eilan, Naomi and Johannes Roessler (eds) 2003: Agency and Self-Awareness. Oxford: Oxford University Press.

Evans, Gareth 1982: Varieties of Reference. Oxford: Clarendon Press.

- 1985: 'Things without the Mind', in his Collected Papers. New York: Oxford University Press, pp. 248-90.

Foster, John and Howard Robinson (eds) 1985: Essays on Berkeley. Oxford: Clarendon Press.

Freksa, Christian et al. (eds) 1998: Spatial Cognition: An Interdisciplinary Approach to Representing and Processing Spatial Knowledge. Berlin: Springer.

Gibson, James 1979: The Ecological Approach to Visual Perception. Boston: Houghton Mifflin.

Ginet, Carl 1975: Knowledge, Perception, and Memory. Boston: Reidel.

Goodale, Melvyn and Richard Andersen 1998: 'Frames of Reference for Perception and Action in the Human Visual System'. Neuroscience and Biobehavioral Reviews, 22, pp. 161-72.

Grush, Rick forthcoming: 'Berkeley and the Spatiality of Vision'. Forthcoming in Journal of the History of Philosophy.

2004: 'The Emulation Theory of Representation: Motor control, Imagery, and Perception'. Behavioral and Brain Sciences, 27, pp. 377442. 
2001: 'Self, World and Space: On the Meaning and Mechanisms of Egocentric and Allocentric Spatial Representation'. Brain and Mind, 1, pp. 59-92.

Gupta, Anil 1999: 'Meaning and Misconceptions', in Jackendoff, Bloom and Wynn 1999, pp. 15-41.

Hartfield, Gary 1990: The Natural and the Normative: Theories of Spatial Perception from Kant to Helmholtz. Cambridge, MA: The MIT Press.

Hiraki, Kazuo et al. 1998: 'From Egocentric to Allocentric Spatial Behavior: A Computational Model of Spatial Development'. Adaptive Behavior, 6, pp. 371-91.

Hornsby, Jennifer 2004: 'Semantic Knowledge and Practical Knowledge'. Supplement to the Proceedings of the Aristotelian Society, 79, pp. 107-30.

_ 2000: 'Personal and Subpersonal: A Defence of Dennett's Early Distinction'. Philosophical Explorations, 1, pp. 6-24.

Hurley, Susan forthcoming: 'Varieties of externalism', in Menary forthcoming.

1998: Consciousness in Action. Cambridge, MA: Harvard University Press.

Iachini, Tina and Gennaro Ruggiero 2006: 'Egocentric and Allocentric Spatial Frames of Reference: A Direct Measure'. Cognitive Processing, 7, pp. 126-7.

Jackendoff, Ray, Paul Bloom, and Karen Wynn, (eds) 1999: Language, Logic, and Concepts: Essays in Honor of John Macnamara. Cambridge, MA: MIT Press.

Kelly, Sean 2001: 'The Non-Conceptual Content of Perceptual Experience: Situation Dependence and Fineness of Grain', Philosophy and Phenomenological Research, 62, pp. 601-8.

2004: 'Seeing Things in Merleau-Ponty', in Carman and Hansen, pp. 74-110.

Klatzky, Roberta 1998: 'Allocentric and Egocentric Spatial Representations: Definitions, Distinctions, and Interconnections', in Freska 1998, pp. 1-17.

Marr, David 1982: Vision: A Computational Investigation into the Human Representation and Processing of Visual Information. San Francisco: Freeman Press.

Matthen, Mohan 2006: 'Review of Alva Noë, Action in Perception'. Mind, 115, pp. 1160-6.

2005: Seeing, Doing and Knowing: A Philosophical Theory of Sense Perception. Oxford: Clarendon Press. 
McDowell, John 1994: 'The Content of Perceptual Experience'. The Philosophical Quarterly, 44, pp. 190-205.

Menary, Richard (ed.) forthcoming: The Extended Mind, Aldershot: Ashgate.

Merleau-Ponty, Maurice 1962: Phenomenology of Perception, trans. Colin Smith. London: Routledge.

Mumford, Stephen 1999: 'Intentionality and the Physical: A New Theory of Disposition Ascription'. The Philosophical Quarterly, 195, pp. 215-25.

1998: Dispositions. Oxford: Oxford University Press.

Noë, Alva forthcoming: 'Real Presence'. Forthcoming in Philosophical Topics.

2004: Action in Perception. Cambridge, MA: The MIT Press.

O'Hear, Anthony, (ed.) 2004: Modern Moral Philosophy. Cambridge: Cambridge University Press.

O'Keefe, Brian et al. 1998: 'Knowing Where and Getting There: A Human Navigation Network'. Science, 280, pp. 921-4.

Paillard, Jacques 1991: 'Motor and Representational Framing of Space', in his Brain and Space. Oxford: Oxford University Press, pp. 163-82.

Peacocke, Christopher 1999: Being Known. Oxford: Clarendon Press.

_ 1985: 'Imagination, Experience and Possibility: A Berkeleian View Defended', in Foster and Robinson 1985, pp. 19-35.

1983: Sense and Content. Oxford: Clarendon Press.

Pellegrin, Pierre and Daniel Devereux (eds) 1990: Biologie, Logique, et Métaphysique chez Aristote. Paris: Editions du C.N.R.S.

Pietersma, Henry 1990: Merleau-Ponty: Critical Essays. Washington: University Press of America.

Ryle, Gilbert 1949: The Concept of Mind. Chicago: The University of Chicago Press.

Schellenberg, Susanna manuscript: 'The Situation-Dependency of Perception'.

Shapiro, Larry 2004: The Mind Incarnate. Cambridge, MA: The MIT Press.

Stanley, Jason and Timothy Williamson 2001: 'Knowing How'. The Journal of Philosophy, 98, pp. 411-44.

Strawson, P. F. 1966: The Bounds of Sense: An Essay on Kant's Critique of Pure Reason. London: Routledge.

—_1959: Individuals: An Essay in Descriptive Metaphysics. London: Routledge.

Taylor, Charles 1989: 'Embodied Agency', in Pietersma 1990, pp. 1-21.

1964: The Explanation of Behavior. London: Routledge. 
Thompson, Evan 2007: Mind in Life: Biology, Phenomenology, and the Sciences of Mind. Cambridge, MA: Harvard University Press.

Thompson, Evan and Francisco Varela 2001: 'Radical Embodiment: Neural Dynamics and Consciousness'. Trends in Cognitive Sciences, 5, pp. 418-25.

Thompson, Michael 2004: 'Apprehending Human Form', in O’Hear 2004, pp. 47-74.

Williams, Bernard 1966: 'Imagination and the Self', in his Problems of the Self. Cambridge: Cambridge University Press, 1973, pp. 26-45. 
